artery can be added to the armamentarium of surgeons dealing with coronary artery disease.

We thank Dr Danton Rocha Loures, from the Federal University of Paraná, for help with the technical aspects of the use of the Biocompound-graft.

\section{REFERENCES}

1. Carpentier A, Guermonprez JL, Deloche A, Frechette C, Dubost A. The aorto-to-coronary radial artery bypass graft: a technique avoiding pathological changes in grafts. Ann Thorac Surg 1973;16:111-21.
2. Acar C, Jebara VA, Portoghese M, et al. Revival of the radial artery for coronary artery bypass grafting. Ann Thorac Surg 1992;54:652-9.

3. Dallan LA, Oliveira AS, Lisboa LA, et al. Complete myocardial revascularization with exclusive use of arterial grafts. Rev Bras Circ Cardiovasc 1998;13:187-93

4. Barner HB. Defining the role of the radial artery. Semin Thorac Cardiovasc Surg 1996;8:3-9.

5. Zurbrügg HR, Hetzer R. The use of Biocompound-grafts together with varicose veins: first clinical experience. J Cardiovasc Surg 1996:37(6 Suppl 1):143-6.

\title{
SYMPTOMATIC CORONARY-SUBCLAVIAN STEAL SYNDROME: REPORT OF A CASE WITH COMPLETE OCCLUSION OF PROXIMAL LET SUBCLAVIAN ARTERY AND ANOMALOUS ORIGIN OF LEFT VERTEBRAL ARTERY FROM THE AORTIC ARCH
}

\author{
Eugenio Neri, MD, Enrico Carone, MD, Gianni Capannini, MD, Enrico Tucci, MD, Francesco Diciolla, MD, and
} Carlo Sassi, MD, Siena, Italy

A case of severe resting angina in a patient with a patent left internal thoracic artery (LITA) graft on the left anterior descending coronary artery (LAD), complete occlusion of the proximal left subclavian artery, and anomalous origin of the left vertebral artery from the aortic arch is presented. The clinical picture, hemodynamic pattern, and treatment are described.

A 75-year-old man was admitted with resting angina. Eleven years earlier, the patient had undergone coronary artery bypass grafting (CABG) with the LITA artery to the LAD and saphenous vein grafts for the first diagonal, obtuse marginal, and right coronary arteries. Over the past $1 \frac{1}{2}$ years he had been having exertional angina, and its severity had dramatically increased over the past month. Chest pain could easily be provoked by mild exercise and exacerbated by selective exercise of the left upper limb. Furthermore, during exercise the patient had cramping of the left arm, whose severity increased over time, with symptoms of rest pain during the past month. No symptoms of vertebrobasilar insufficiency could be recorded. As evinced from the patient's file, at the time of the previous operation no difference in pressure between the two arms was recorded and intraoperative assessment of LITA flow was optimal. Preoperative brachio-

From the Thoracic and Cardiovascular Department, University Hospital, Siena, Italy.

Received for publication April 2, 1999; accepted for publication June 3, 1999.

Address for reprints: Eugenio Neri, MD, Istituto di Chirurgia Toracica e Cardiovascolare Universitá degli Studi di Siena, Policlinico le Scotte, Viale M. Bracci, 53100 Siena, Italy.

J Thorac Cardiovasc Surg 1999;118:565-7

Copyright $\odot 1999$ by Mosby, Inc.

$0022-5223 / 99 \$ 8.00+0 \quad \mathbf{1 2 / 5 4 / 1 0 0 4 0 4}$ cephalic arteriography was not performed, but a postoperative cineangiogram obtained 1 year after CABG surgery showed perfect patency of the LITA and absence of significant stenosis on the left subclavian artery.

At physical examination the left humeral pulses were absent and the left arm was cold and pale. The patient maintained a peculiar position, resting his left arm on his right arm to alleviate the pain. Arterial pressure in the left arm could not be recorded, whereas pressure in the right arm was 176/95 $\mathrm{mm} \mathrm{Hg}$.

An electrocardiogram revealed myocardial ischemia in leads $V_{1}$ to $V_{5}$ with an ST-T segment depression of $2 \mathrm{~mm}$; ischemic changes could be exacerbated by mild exercise of the left arm. Cardiac enzymes were within normal limits. Echocardiography showed mild anterolateral wall motion abnormalities. Arterial Doppler echography showed normal flow in the vertebral arteries. No subclavian steal was demonstrated, and no abnormalities of the carotid and vertebral arteries were recorded, although the left humeral artery showed extremely low flow. According to cardiac catheterization, the coronary anatomy had not changed since the CABG operation. Important proximal stenoses were present on the $\mathrm{LAD}$, in its major diagonal branch, in first the obtuse marginal, and in the right coronary artery. Selective graft opacification showed patent saphenous vein grafts. Visualization of the LITA was not possible because of proximal occlusion of the subclavian artery. Patency of the LITA could be demonstrated by retrograde opacification of the vessel during selective catheterization of the LAD (Fig 1). The distal subclavian artery was visualized by retrograde opacification of the LITA. The left vertebral artery took origin directly from the aortic arch (Fig 2). By direct opacification of the vertebral artery, the distal subclavian artery could be 


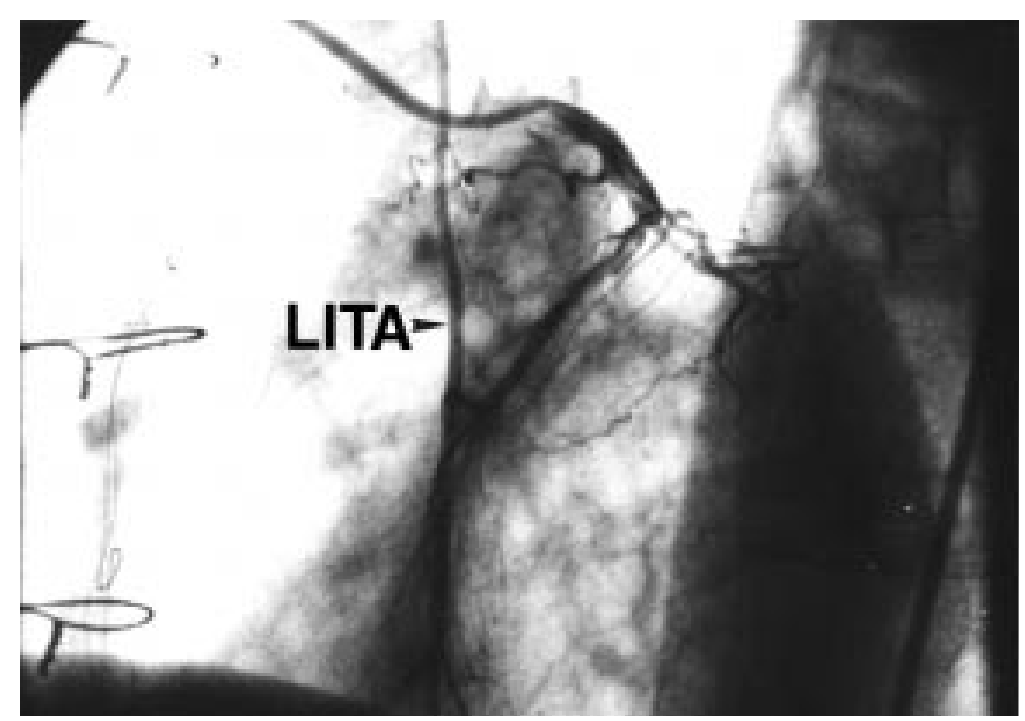

Fig 1. Present-time cineangiography showing the reversal of flow in the left internal thoracic artery (LITA).

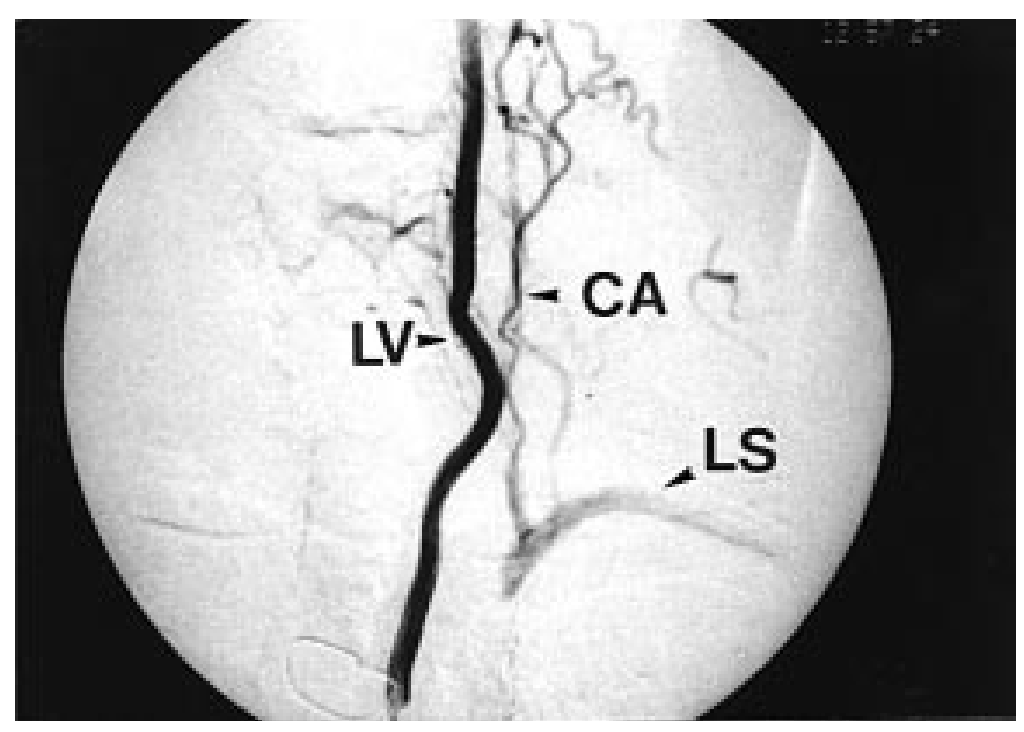

Fig 2. The left vertebral artery $(L V)$ takes origin directly from the aortic arch. The distal subclavian artery $(L S)$ is visualized in the late phase through small cervical arteries $(C A)$ taking origin beyond the occluded portion.

visualized in the late phase through small cervical arteries taking origin beyond the occluded portion (Fig 2).

The patient was scheduled for urgent carotid-subclavian bypass surgery. A prosthetic 8-mm Dacron bypass graft from the carotid to the subclavian artery was inserted by way of a left supraclavicular incision, under systemic heparinization. The postoperative course was uneventful with immediate normalization of the electrocardiogram and complete relief of symptoms.

Discussion. The use of the ITA in CABG procedures predisposes to the onset of the coronary-subclavian steal syndrome. The syndrome is due to the stenosis or occlusion of the subclavian artery proximal to the origin of the ITA. The stenosis results in retrograde flow in the ITA and steal from the coronary artery, causing ischemia to the area supplied by the graft. ${ }^{1,2}$ The coronary-subclavian steal syndrome is often associated with a vertebral steal syndrome because of the anatomic origin of the left vertebral artery from the left subclavian artery. ${ }^{3-5}$ Subclavian steal provides collateral flow to the arm and the heart, alleviating ischemia in these regions. Coronary-subclavian steal syndrome is always suspected in patients with recurrent angina after CABG with an ITA, when a pressure gradient between the right and left arms is demonstrated. ${ }^{1,2}$ The coexistence of verte- 
brobasilar insufficiency symptoms may facilitate the clinical diagnosis. ${ }^{2}$

In the presented case, the anomalous origin of the vertebral artery from the aortic arch (Fig 2) determines a peculiar situation in which severe resting angina and left arm hypoperfusion contrast with the absence of neurologic symptoms of vertebrobasilar insufficiency. The absence of residual flow through the subclavian artery and the absence of collateral flow by the vertebral artery, apart from the moderate supply by little cervical branches (Fig 2), explain the degree of coronary steal through the ITA and the clinical picture of severe ischemia of the left arm. To our knowledge, this peculiar anatomic pattern has not previously been reported. Aside from its unusual clinical presentation, this case underlines that coronary-subclavian steal, although uncommon, is sufficiently important to consider when recurrence of angina after CABG operations is observed.

\section{REFERENCES}

1. Marshall WG Jr, Miller EC, Kouchoukos NT. The coronarysubclavian steal syndrome: report of a case and recommendations for prevention and management. Ann Thorac Surg 1988;46: 193-6

2. FitzGibbon GM, Keon WJ. Coronary subclavian steal: a recurrent case with notes on detecting the threat potential. Ann Thorac Surg 1995;60:1810-2.

3. Takach TJ, Beggs ML, Nykamp VJ, Reul GJ Jr. Concomitant cerebral and coronary subclavian steal. Ann Thorac Surg 1997;63:853-4.

4. Saydjari R, Upp JR, Wolma FJ. Coronary-subclavian steal syndrome following coronary artery bypass grafting. Cardiology 1991;78:53-7.

5. Sureyya Ozbek S, Parildar M. Hemodynamic disorders in internal thoracic artery: How often are they associated with subclavian steal via ipsilateral vertebral artery?. J Ultrasound Med $1998 ; 17: 147-51$ 